\title{
Ecos de lo oculto en el Buenos Aires de entre-siglos: INTERVENCIONES DE ESCRITORES E INTELECTUALES EN MEDIOS DE PRENSA*
}

\author{
Soledad Quereilhac**
}

\section{Resumen}

El presente trabajo analiza las intervenciones de intelectuales y de escritores en diferentes medios de prensa argentinos sobre la cuestión de las ciencias ocultas, durante los años de entre-siglos. El rastreo de estas intervenciones -tanto en revistas espiritistas y teosóficas (Constancia, Philadelphia), como en los diarios y revistas de circulación masiva (La Nación, Caras y Caretas)- permite apreciar no sólo el relativo protagonismo de la cuestión del ocultismo, ligado aún a los intereses de algunas ciencias "positivas", sino también el amplio espectro de posiciones -tanto ideológicas como "sensibles"- que adoptaron ciertos escritores e intelectuales del período.

Palabras clave: escritores, medios de prensa , espiritismo, ocultismo, entresiglos.

\section{Writers, PRESS AND OCCULTISM IN BUENOS Aires BETWEEN CENTURIES}

\begin{abstract}
The present paper analyzes the participation of intellectuals and writers in Argentine newspapers and magazines, with regard to the question of occult sciences, during the years of between-centuries. We are interested in a corpus of texts published as much in spiritists and theosophical magazines (Constancia, Philadelphia), like in newspapers and magazines of massive circulation (La Nación, Caras y Caretas). The tracking of these articles and brief essays not only allows to appreciate the importance of the occultism, related to its proximity with some "positive" sciences, but also the multiple positions that assumed certain writers and intellectuals of the period.
\end{abstract}

Key words: writers, press, spiritism, theosophy, between centuries.

Recibido: 08-04-2013

Aceptado: 03-06-2013

* Una versión más acotada de este trabajo fue leída en el Primer Encuentro Regional: Itinerarios periodísticos de intelectuales y escritores en América del Sur (1870-1950), Instituto de Historia Argentina y Americana Dr. Emilio Ravignani - Pehesa, Facultad de Filosofía y Letras, UBA CONICET, realizado en Buenos Aires el 14 de marzo de 2013. Organización a cargo de las Dras. Sylvia Saítta (Argentina), Claudia Roman (Argentina) y Marina Alvarado (Chile).

** Argentina, Doctora en Letras de la Universidad de Buenos Aires, Investigadora del Consejo Nacional de Ciencia y Tecnología (CONICET), con sede en el Instituto de Historia Argentina y Americana "Dr. Emilio Ravignani", Facultad de Filosofía y Letras, UBA, Docente de la materia "Problemas de la Literatura Argentina", Departamento de Letras, FFyL, UBA, Buenos Aires, Argentina. solquerei@gmail.com 
En los años de entre-siglos, el auge de las prácticas e instituciones vinculadas al mundo de las ciencias ocultas, el espiritismo y otras corrientes que fusionaron lo espiritual con las inquietudes modernas, incentivó las intervenciones de escritores e intelectuales en diferentes medios de prensa porteños. Pronunciarse sobre esta materia y evaluar el nivel de verdad, empirismo o validez científica de las diversas manifestaciones del más allá y de lo paranormal, pareció ser un ejercicio recurrente de muchos escritores de la época, independientemente de su orientación estética o ideológica en general. Si bien se trataba de un tema de sostenida vigencia en Buenos Aires desde, por lo menos, la década del setenta del siglo XIX, un aspecto que convocaba el artículo de opinión, la reseña del caso singular o el testimonio de las propias experiencias con los fenómenos suprasensibles, era su eventual cotejo con los criterios de medición y verificación de las ciencias físico-naturales o, en otras ocasiones, sus posibles aportes a una "ciencia del espíritu", que ahondara en la investigación de la psiquis humana. Pero por sobre todo, en la mayoría de los casos, era el supuesto empirismo de los fenómenos, aún no atado a una explicación definitiva pero asombroso en sí mismo, lo que constituía el centro de interés de las comunicaciones.

El relevo de las noticias sobre temas ocultistas, espiritistas y teosóficos en los diarios de mayor circulación de Buenos Aires, como La Nación, o en las revistas ampliamente leídas, como Caras y Caretas, es un valioso indicador de la renovada vigencia que adoptaba la colocación liminar de los fenómenos misteriosos respecto de lo científico. Además de lo que han aportado la historia de las ideas y los estudios de las producciones intelectuales más elaboradas de la época sobre la "cultura científica" (Terán, 2000; Barrancos, 1996; Biagini, 1986), relevar la sostenida frecuencia con que los medios de prensa destinados al gran público atendían temas relacionados a los misterios del espíritu, desde perspectivas que recorrían todo el espectro entre la seriedad informativa y la chacota informal, permite leer la fuerza de ciertas representaciones sociales que circulaban por fuera de los ámbitos intelectuales o académicos. El hecho de que el diario La Nación, por ejemplo, publicara con frecuencia, durante varias décadas, artículos sobre las ciencias ocultas, con perspectivas que combinaban, en diferentes grados, la legitimación y el escepticismo, no era síntoma de que el diario hubiera perdido su curso, sino indicador de

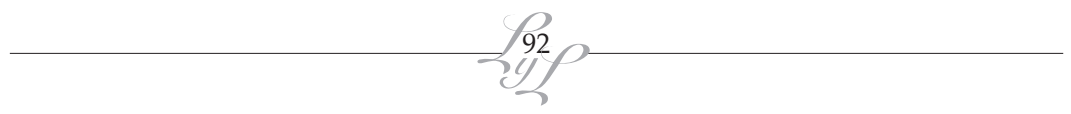


la relevancia que ese horizonte de lo posible tenía en los años de entresiglos. ${ }^{1}$

Es, justamente, con este tipo de representaciones periodísticas del mundo de lo oculto y de lo espiritual que los escritores e intelectuales dialogaban cuando intervenían en los medios de prensa masivos. Porque si bien consideramos en este trabajo figuras con formación y ubicación disímil en el campo cultural -Eduardo L. Holmberg, un naturalista, que escribe literatura en sus ratos libres; Leopoldo Lugones, un escritor miembro de la Sociedad Teosófica; Juan José Soiza Reilly y Roberto Arlt, escritores que ejercerían el periodismo como profesión; José Ingenieros, un médico e intelectual referente del positivismo argentino, entre otros-, es cierto que en todos los casos, cuando se trata de intervenir en la inmediatez del periódico, no es sólo desde su formación previa que se construye la enunciación o, en el caso de los escritores, no siempre se habla en sintonía con cómo se han trabajado los misterios de lo oculto en clave literaria, donde siempre pesa, además, la tradición formal del fantástico, sino que a ello se suma la interacción con una representación vulgarizada, más masiva, periodística, de estos temas, representación con la que tenía mayor contacto el público lector.

Por otra parte, cuando recorremos las intervenciones periodísticas de intelectuales y escritores sobre un tema tan maleable, laxo y opinable como el de las ciencias ocultas, que carece de figuras de autoridad unánimes como en otros campos, se hace notable cuánto terreno quedaba abierto para la especulación y la proyección de sueños propios.

\section{Espectros en la prensa porteña}

Durante sus años de residencia en Buenos Aires, Rubén Darío publicó un puñado de artículos vinculados a lo oculto y a los misterios

1 A lo largo de las décadas de entre-siglos, es posible encontrar en el diario La Nación, con una frecuencia mensual, y por períodos semanales, notas vinculadas a un amplio y heterogéneo campo de "lo científico", cuyos títulos demuestran por sí solos dicha heterogeneidad; de manera aleatoria, podemos citar: "El espiritismo en Buenos Aires", 20 de diciembre de 1891; Carlos du Prel, "Ilusiones ópticas", "Fotografía de lo invisible", "Imperfección de los sentidos", serie de notas publicadas entre marzo y abril de 1896; "La luz de Rontgen. Experiencias interesantes en la Facultad de Matemáticas", 13 de marzo de 1896; "Médiums y espíritus. Los rayos catódicos", 18 de octubre de 1897; "Espectros", 29 de diciembre de 1905; "Informe de Lombroso sobre casas encantadas", 20 de julio de 1906; Enrico Ferri, "La ciencia en el siglo XX" (conferencia pronunciada en Buenos Aires), 29 de julio de 1908. Títulos muy similares hemos rastreado en el diario La Prensa en el mismo lapso. 
del más allá en el diario La Nación ${ }^{2}$. En 1902, envió desde París tres colaboraciones sobre los milagros de la virgen de Lourdes, en las que releía este mito del catolicismo con las nuevas herramientas que proveía el desarrollo de las ciencias ocultas y la difusión de los fenómenos paranormales. En sintonía con lo que también difundían los principales diarios parisinos, Darío comenzaba así sus envíos a Buenos Aires:

He creído oportuno, pues -en Buenos Aires hay muchas gentes estudiosas y aficionadas a esta clase de investigacionesocuparme en este asunto [los milagros de Lourdes]; y me he dirigido a un amigo mío muy versado en lo que pasa de tejas arriba, artista, teólogo, perteneciente a los círculos swedemborguianos y espíritu convencido. He hablado ya de él en otra ocasión: me refiero a G. Núñez. [...].

Debo advertir que creo en absoluto en la sinceridad de mi amigo. A pesar de que muchas veces he oído de sus labios narraciones, sucedidos y hechos personales que parecerían increíbles, no me han sorprendido tanto, después de haberme dedicado, en otros tiempos, a lecturas teosóficas y ocultistas. Las historias y experimentos de Núñez, no me parece que sobrepasen a lo que todos conocemos en William Crookes, H. P. Blavatsky, Richet, Lombroso y tantos otros. Núñez es un ocultista cristiano; y, repito, es un hombre sincero. Es este el principal valor de su opinión. ${ }^{3}$

A continuación, Darío reprodujo el testimonio de Núñez a lo largo de tres entregas, en donde daba fe de la autenticidad de los dichos "milagros". Con todo, en otras colaboraciones, también desde París pero en 1906, Darío se mostraba algo más escéptico, a pesar de que en esta oportunidad se trataba de una experiencia realizada por un científico reconocido, futuro Premio Nobel, el fisiólogo Charles Richet, quien dio a conocer las fotografías obtenidas durante una "materialización" de una entidad a través de una médium. Los diarios de París reprodujeron sus fotografías, que llegaron pronto, también, a los diarios porteños; su evidente rusticidad, aun para los criterios de época, contrastaba no obs-

2 Un índice de buena parte de las colaboraciones de Darío se incluye en la compilación de Susana Zanetti (2004). Sin embargo, algunos artículos vinculados al espiritismo y las ciencias ocultas, como los que aquí nos ocupan, no fueron tenidos en cuenta para ese libro.

3 "Los milagros de Lourdes", publicado en La Nación y reproducido en su totalidad por Constancia, Buenos Aires, 6 de febrero de 1902. Incluido también en La caravana pasa (1917). 
tante con las palabras de una autoridad como Richet, tan convencido de haber presenciado un fenómeno empírico, real, cuya explicación, no obstante, aún no arriesgaba.

Tanto Rubén Darío como José Ingenieros, que también se hallaba en París en ese momento, enviaron sus colaboraciones a La Nación pronunciándose sobre el asunto. Las palabras de Darío eran amenas, pero escépticas. Se inclinaba por la hipótesis de la buena fe del científico, pero atribuía poca veracidad a las pruebas, y ello es curioso, dado que frente a los milagros de una virgen, Darío tendía a ser más crédulo. Ingenieros, por su parte, cuatro días antes, había sido lapidario con Richet, a pesar de manifestar su pasada admiración por el fisiólogo. Trató de "zonzo" a su colega, de "histérica" a la médium, y con ello despertó airadas críticas de los espiritistas de Constancia, que dedicaron columnas de varios números de su revista para retrucarle. Veremos más adelante otras intervenciones de Ingenieros.

Años más tarde, en su Autobiografía, Rubén Darío fue más preciso respecto de su vínculo con el ocultismo. Sobre todo durante sus años de residencia en Buenos Aires, compartió su afición con sus amigos Leopoldo Lugones y Patricio Piñeiro Sorondo, sobrino del líder de la primera Rama de la Sociedad Teosófica en Argentina, Alejandro Sorondo. En las tardes de trabajo que los tres compartían en la dirección general de Correos y Telégrafos, conversaban sobre teosofía -de cuya sociedad Lugones era miembro activo- y otras filosofías antiguas. Darío admitía haber presenciado fenómenos paranormales y espiritistas, como el encuentro con un fantasma en la plaza de la catedral de León, en Nicaragua (hecho que constituirá el argumento de su relato "La larva", de 1910), o el "anuncio psicofísico del fallecimiento de [un] amigo [...] en los mismos momentos en que él moría en la ciudad de Panamá" (Darío, 1968, 127). También, recuerda el encuentro en París, junto a Leopoldo Lugones, con el Dr. Encausse, alias Papus, prestigioso médico y ocultista de la época, de quien obtuvieron demostraciones asombrosas sobre sus poderes psíquicos. Y aquí, en su Autobiografía, ya no hay reparos de credulidad, sino que llamativamente, confiesa que debió tomar distancia del mundo de lo oculto por razones de salud: "Me había dado desde hacía largo tiempo a esta clase de estudios, y los abandoné a causa de mi extremada nerviosidad y por consejo de médicos amigos. [...] $[\mathrm{N}] \mathrm{o}$ he seguido en esta clase de investigaciones por temor justo a alguna perturbación mental" (Darío, 1968, 128). En cierta medida, los relatos 
fantásticos que escribió durante sus años en Buenos Aires, algunos de los cuales se publicaron también en La Nación, expresan con el lenguaje de la literatura, el tipo de vínculo sensible, antes que intelectual, que Darío tuvo con estas experiencias: la atracción por un ámbito misterioso pero que, como en los personajes de Poe, puede herir los nervios de muerte y conducir a la locura. Lejos de la "racionalidad" y, por qué no, el arrojo temerario con que los personajes de Lugones se inician en el manejo de las ciencias ocultas, los personajes de Darío -livianos, casi anecdóticos en su perfil- se topan con el misterio pero rápidamente encuentran la salida risueña o irónica como conjuro, casi como antídoto. "Thanatopia”, "El caso de la señorita Amelia" o "La extraña muerte de Fray Pedro" son ejemplos de esas salidas risueñas, que descomprimen la densidad del ocultismo. ${ }^{4}$ No hay en Darío una búsqueda de conocimiento científico a través del mundo oculto, sino la experiencia fugaz del misterio, el miedo, lo insólito, que impacta a nivel de los sentidos y que ofrece sensaciones con potencial literario.

El caso de Ingenieros es ciertamente diferente, aunque presenta también sus ambivalencias, acaso más notorias por tratarse de un médico y no de un poeta. En 1898, cuando tanto Alfredo Palacios como Leopoldo Lugones se iniciaron como jóvenes miembros de la Sociedad Teosófica, Ingenieros también publicó, como ellos, un artículo en el órgano de dicha institución, la Revista de Estudios Teosóficos Philadelphia, si bien nunca se incorporó como miembro de la Rama. Su visión, allí, de las ciencias ocultas era ciertamente positiva; llamaba "verdaderos hombres de ciencia" a los ocultistas experimentadores, de quienes la humanidad debía "esperarlo todo, pues tienden precisamente a romper toda barrera que intente oponerse a la libre investigación de lo desconocido" (Ingenieros, 1898). Un año antes, había publicado un artículo de características similares en el periódico La Montaña (Ingenieros, 1897). Pero sus vínculos con la teosofía no avanzaron más allá de estos tímidos comienzos. Algo similar, acaso con mayores tropiezos, sucedió con los espiritistas de la Sociedad "Constancia", presidida por Cosme Mariño. En 1903, leemos en la portada de la revista Constancia, una "Carta abierta" a Ingenieros, firmada por Pedro Serie, miembro de la entidad

4 "Thanatopia", fechado "Buenos Aires, 1893" y publicado luego en Cuentos completos, pp. 187-192. "El caso de la Señorita Amelia", La Nación, Buenos Aires, $1^{\circ}$ de enero de 1894, (Cuentos completos, pp. 226-231). "La extraña muerte de Fray Pedro", Mundial Magazine, París, mayo de 1913, (Cuentos completos, pp. 325-329) 
y secretario de Florentino Ameghino en el Museo de Ciencias Naturales. En ella, se revelan dos cosas, a modo de disimulada infidencia: por un lado, que Ingenieros ha enviado una carta a la Sociedad solicitando presenciar una sesión con médiums; por otro, que en su revista Archivos de Psiquiatría y Criminología se muestra crítico de los fenómenos espiritistas, a los que "clasifica de empíricos, sin carácter científico", a pesar de no haber presenciado nunca una sesión (Serié, 1903). Al año siguiente, los espiritistas todavía no contaban con la presencia de Ingenieros en sus sesiones, pero sí podían exhibir orgullosos en su revista un adelanto de su futuro libro, Los accidentes histéricos. Estudios de psicología experimental, clínica y terapéutica, para que fuera difundido en la sección "Transcripciones" (Ingenieros, 1904). El capítulo elegido, "Interpretación científica y valor terapéutico del hipnotismo y la sugestión", representaba indudable interés para los espiritistas y, sobre todo, para quienes integraban también, simultáneamente, la Sociedad Magnetológica.

Pero esta auspiciosa relación entre "pares" fue fugaz. Dos años más tarde, los integrantes de Constancia se indignaron con lo que Ingenieros publicó en La Nación acerca de los informes de Richet, que ya hemos mencionado. ${ }^{5}$ El exceso de encono para con Ingenieros se explica, casi, con la lógica del amante despechado, aunque en esta caso, se trataría de una relación nunca consumada. La gran esperanza de los espiritistas porteños era incorporar a sus filas a un representante de la "ciencia oficial" equivalente a un Crookes en Inglaterra o a un Lombroso en Italia, y esa ambición encontraba su meta ideal en José Ingenieros, médico e intelectual prestigioso que hubiera consagrado para siempre su institución. Ingenieros nunca aprobó la hipótesis de los espiritistas, pero en 1918, finalmente, acudió a "Constancia" para presenciar las dotes del famoso médium platense Osvaldo Fidanza, de la Sociedad "Luz del Porvenir", quien ya desde la década anterior era protagonista de sesiones en las cuales se obtenían fotografías de materializaciones, levitaciones y otras curiosidades. ${ }^{6}$ Acompañado también por otros "profanos" como Constancio C. Vigil (director de "Atlántida") y redactores de La Nación y La Prensa, Ingenieros tomó nota de lo allí ocurrido pero

5 La Redacción, “Ingenieros y las experiencias de Richet”, Constancia, 11 de febrero de 1906.

6 Los resultados se informaron en varias entregas de la revista Constancia, con el título "Fenómenos de aportes y fotografías experimentados en La Plata", con fecha del 11 de febrero y el 18 de marzo de 1906. 
no dejó testimonio en la revista. Entre quienes también habían sido invitados y se negaron a asistir se hallaban Leopoldo Lugones, Enrique Gómez Carrillo y Horacio Piñeiro. ${ }^{7}$ La Sociedad "Constancia" había programado una serie de futuras sesiones a lo largo de esos meses, pero el proyecto se vio interrumpido cuando el médium fue herido por un fanático religioso. Y allí se frustró, nuevamente, el último acercamiento a Ingenieros. Acaso mi investigación en curso sobre los vínculos de Ingenieros con espiritistas y teósofos arroje, en el futuro, nuevo material de análisis.

Por su parte, Leopoldo Lugones fue un declarado teósofo y así lo he trabajado en dos capítulos de mi tesis doctoral (Quereilhac, 2010), de modo que no redundaré en el tema. Agregaré, sí, un breve comentario, no ya sobre sus relatos donde ciencia y ocultismo se representan fusionados (en Las fuerzas extrañas de 1906 y en otros dados a conocer en Caras y Caretas), ni sobre sus ensayos en Philadelphia, sino sobre su forma de proyectar su interés por lo oculto en la lectura de sus pares: en este caso, la curiosa reseña sobre la breve novela Nelly (1896) de Eduardo L. Holmberg, que Lugones publica en el diario El Tiempo. Son menos las líneas que Lugones dedica a analizar la obra que aquellas en las que se devanea por las tradiciones esotéricas de la antigüedad y de la modernidad; no es difícil notar que, tal como está escrita, Nelly no le parece una gran obra a Lugones. De hecho, señala que no le gusta el final (porque allí los personajes relativizan el hecho sobrenatural), ni el término 'histerismo de ultratumba', ni el estilo en general ("fluidas prosas y correctos versos"), al tiempo que reprocha a Holmberg "no habernos dicho lo que piensa de los fenómenos que parece aceptar" (Lugones, 1896). En efecto, si bien Holmberg trabajaba en sus novelas con el espiritismo, nunca se declaró adherente a este tipo de creencias por fuera de lo literario. Con todo, Lugones celebra en Nelly no sólo la "novedad" de su tema para la literatura argentina, sino, llamativamente, que dé cuenta de fenómenos que él considera "reales":

La novela citada no puede ser más real, ni más lógica. Esa telepatía, esas materializaciones, han sido palpadas, vistas, oídas, pesadas, fotografiadas, constatadas, interrogadas.

7 "Sesión medianímica con Fidanza", Constancia, Buenos Aires, 4 de agosto de 1918; "La primera sesión de Fidanza en la Capital", Constancia, Buenos Aires, 6 de octubre de 1918.

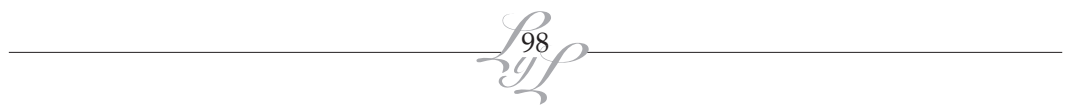


Lombroso ha visto y tocado las manos del espíritu asistente de Eusapia Paladino. Crookes hizo lo mismo con Katie King, la amiga astral del médium Florencia Cook. Wallace, Edmonds, [de] Rochas, Zoelner, Gibier, también han podido estudiarlas con sus graves criterios de sabios. (Lugones, 1896).

Lugones no lee la obra en clave fantástica, sino como una forma estética de la verdad, que ha tomado de las ciencias y de lo que él llama "Ciencia Esotérica", con mayúsculas, nuevos materiales para sus argumentos. Es en este sentido que celebra que "un hombre de ciencia" se ocupe, estéticamente, de cuestiones tan serias como la telepatía y la comunicación desde el más allá. A sólo un año de esta reseña, Lugones comenzó a publicar sus primeros relatos cientificistas, como "Kabala práctica", "El Psychon" y "El espejo negro". ${ }^{8}$

Esas "pizcas de ironía" que molestaban a Lugones en el relato de Holmberg, atribuidas a cierto "materialismo ortodoxo", representaban apenas una zona de su posición respecto de las ciencias ocultas. Naturalista de profesión, médico de formación y escritor en sus tiempos libres, Holmberg estaba al tanto, desde la década del setenta, del auge del espiritismo en los países del norte y de su pregnancia en reconocidos hombres de ciencias, entre ellos un naturalista como él, Alfred R. Wallace, cuya adhesión al espiritismo era pública. Pero a lo largo de mi investigación, no he hallado a Holmberg cerca de estas corrientes. Con todo, en la primera década del siglo XX, el por entonces Director del Zoológico de Buenos Aires y responsable de la divulgación científica en Caras y Caretas, publicó tres colaboraciones en ese semanario en las que se observa el tanteo por tres perspectivas que se excluyen entre sí: en primer lugar, la afirmación de que existen fenómenos empíricos atemorizantes, que carecen de explicación y ante los cuales aún estamos en ayunas; prueba de ello es el relato, casi anécdota, "Nunca se supo", en el que se afirma que una familia debió abandonar su casa por causa del acoso de un animal o ser inclasificable, que dejaba rastros de plumas, algodón y pelos, pero cuya naturaleza había dejado mudos a químicos y naturalistas. Se trata de la concepción más clásica del misterio, muy presente en la literatura fantástica y de terror (Holmberg, 1903). Pero

8 El primero, publicado en El Tiempo, n 949, 22 de noviembre de 1897. Los siguientes en Tribuna, 31 de enero de 1898 y 17 de noviembre de 1898 , respectivamente. Compilados posteriormente por Barcia (1998). 
años más tarde, con "El fantasma", Holmberg tantea otra perspectiva: con la anécdota del paisano que corrió kilómetros sobre su caballo, presa del miedo, convencido de que un demonio estaba sobre su espalda, cuando sólo se trataba de su sombrero, transmite la idea de que la ignorancia produce la superchería, y que su remedio no es otro que la educación (Holmberg, 1906). Finalmente, el tercer texto, "Las luces malas", propone una perspectiva intermedia, no tan alejada de los espiritualismos con ambiciones científicas: en tertulia de jóvenes científicos, se narran diferentes encuentros con las mal llamadas "luces malas", fenómenos químicos que la mayoría había podido reproducir en sus laboratorios. Sin embargo, todos admiten que aún hay "luces" inclasificables, cuya naturaleza la ciencia aún no ha podido estudiar (Holmberg, 1911). El espectro de estas tres perspectivas es representativo de la inestabilidad de la materia en la época, así como de las variables que estaban en juego en torno de las categorías de "lo posible" y "lo desconocido": la superstición, lo incognoscible y lo asombroso pero real.

En la segunda década del siglo XX, la cuestión de las ciencias ocultas no perdió vigencia en los diarios, pero una zona de sus representaciones comenzó a verse obligada a volcar la mirada hacia atrás, esto es, a armar el raconto de sus orígenes, y centrarse en las décadas de su mayor esplendor, décadas que no eran, por cierto, las contemporáneas. Hay dos crónicas que se destacan: la que con el título abarcador de "Las ciencias ocultas en Buenos Aires. El espiritismo" publica Juan José Soiza Reilly en Fray Mocho (1912); y “Una sesión de fenómenos psíquicos con el Dr. Aristóbulo del Valle", publicada en El Diario por Lob-Nor (1915), alias ocultista de Federico Fernández, decano de la teosofía local. En ambos artículos hay profusas referencias al pasado, si bien en la de Soiza Reilly también se destaca la actualidad del espiritismo, movimiento al que se le atribuye treinta mil adeptos en 1915, dato dudoso como la mayoría de los que ofrece su artículo, de corte algo desprolijo y sensacionalista.

La colaboración de Lob-nor, que reseña en detalle la mudez atónita del "gran orador" Del Valle frente a los fenómenos medianímicos, que al parecer aceptaba, nos retrotrae a una época en que era frecuente que los hombres de la elite intelectual y política se acercaran a Cosme Mariño para presenciar sesiones. Fue el caso de Miguel Cané, a quien Mariño calificó de "espiritista vergonzante" en sus memorias (1963, p. 49), y que en dos manuscritos recientemente hallados en el Archivo General

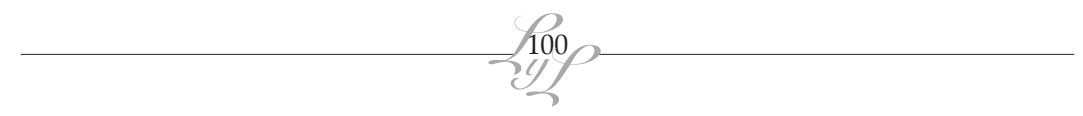


de La Nación, ${ }^{9}$ sin fecha explícita, da cuenta de las numerosas sesiones de las que participó y de su posición al respecto: no cree en los espíritus, pero asegura que el fenómeno de la levitación de la mesa es innegable. Al carecer de explicación y al sentir el absurdo inherente al hecho, arroja una frase que sintetiza su posición: "he visto cosas que no creo". Hacia el final de uno de los manuscritos, dirigido a un amigo que le ha solicitado que asentara su posición respecto del espiritismo, concluye:

[...] repitiendo las palabras de Mr. Crookes, 'sería cobardía callarlo' que los movimientos de la mesa, espontáneos y contra las leyes de la gravitación algunos de ellos, no me ofrecen hoy duda alguna. Los he observado en circunstancias tan diversas, en tan repetidas ocasiones, que mi espíritu, anhelando la lógica y la armonía, se ha abrazado a la idea de una fuerza nueva, desconocida para la ciencia, pero cuyos elementos me son tan familiares.

La conclusión, de notable sinceridad, contrasta con lo que al parecer el mismo Cané declaró en el diario El Nacional, luego de presenciar una sesión con el médium Camilo Bredif, famoso en las décadas del setenta y del ochenta del siglo XIX. A instancias de su amigo, el ingeniero Carlos Encina, estudioso del espiritismo, Cané aceptó experimentar con el médium en su propia casa, pero no se convenció: en El Nacional llamó "taumaturgo" al médium. Con todo, quizás ambos episodios no fueran excluyentes: en el manuscrito anteriormente citado, al referirse al hombre que actuaba de "médium", dice haber "desconfiado de su buena fe, muchas veces sin darme el trabajo de disimularlo". ${ }^{10}$ Mientras que los fenómenos que involucraban el movimiento autónomo de objetos, sí conquistaron su credulidad.

Como sea, durante el último tercio del siglo XIX, aún era posible defender con ciertos argumentos cientificistas el empirismo de estos hechos inexplicables, posibilidad que fue mermando con el avance del siglo. Acaso la desprolija variedad de registros que empleó Soiza Reilly en su nota -desde el racconto histórico fundamentado, hasta la invención de una sesión espiritista en la que el propio Rosas habría insultado

9 Sus fechas de producción aún no han sido establecidas; personalmente, estimo que las fechas oscilan entre fines de la década del 70 y comienzos del 80, años en los que actuaba el médium Camilo Bredif en Buenos Aires. Agradezco a mi compañero de cátedra, el doctorando Juan Pablo Canala, por el conocimiento de dichos manuscritos.

10 El episodio de Cané y Encina con el médium Brédif ha sido narrado por Felipe Senillosa en dos oportunidades $(1891 ; 1885)$. 
al fantasma de Florencio Varela- ${ }^{11}$ informa sobre la paulatina conversión del mundo de lo oculto desde su inicial aspiración al cientificismo, a tema atractivo para la nota periodística de color.

\section{La sospecha sobre los espectros}

A partir de la década del diez, los temas de las ciencias ocultas siguieron estructurando con eficacia muchas ficciones fantásticas de la literatura, como los relatos de Horacio Quiroga, deudores de ese imaginario y su relación con el cientificismo hasta en su último libro, Más allá (1935); como la "fantasía científica" de Ricardo Rojas, publicada en La Novela Semanal, llamada "La psiquina" (Rojas, 1917); o como algunos relatos del libro Cuentos fatales (1924), de Leopoldo Lugones. En cambio, fueron mermando paulatinamente los estudios científicos que dieran validez al empirismo de los fenómenos y con los años, los espiritistas y otros ocultistas sólo pudieron citar como autoridades científicas a nombres del siglo XIX. Uno de los últimos referentes de prestigio fue el médico y escritor inglés Arthur Conan Doyle, quien se unió al espiritismo tras la muerte de su hijo en la Primera Guera Mundial y quien escribió una de las más completas historias del espiritismo (1926), centrada en el mundo anglosajón. Es a propósito de Conan Doyle y las supuestas comunicaciones con los muertos que Horacio Quiroga escribe una de sus más tardías colaboraciones en Caras y Caretas, "El espiritismo y la caja de fósforos" (1926). A pesar de ser un texto contemporáneo a la publicación de sus cuentos "fantasmagóricos" ("El espectro", 1921; "Más allá", 1927; “El puritano", 1926; "El vampiro”, 1927), su posición es reacia y escéptica respecto de los espíritus, concretamente, respecto de las premoniciones y advertencias sobre los accidentes que eventualmente realizarían las ánimas desde el más allá. Y si bien admite Quiroga cuán vital y romántico es querer volver a encontrarse con los seres queridos que han desaparecido, su credulidad no logra participar del mundo espiritista. Acaso su mejor respuesta para ese anhelo hayan sido sus relatos fantásticos.

11 Soiza Reilly inventa este diálogo:

"-Espíritu - preguntó Rosas -¿quién eres?

La mesa respondió sin vacilar de acuerdo con las letras de la clave:

- Florencio Varela.

- ¿Qué quiere ese canalla? - exclamó enfurecido el tirano, hablando con la mesa.- ¡Hable, canalla!

- ¡A...s...e...s...i...n...o! - concluyó la mesita. Don Juan Manuel disolvió la tertulia a rebencazos."

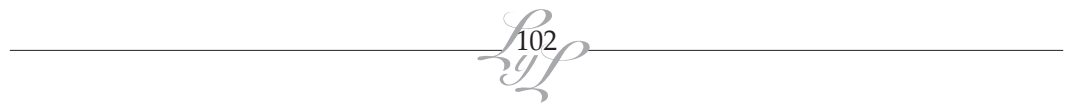


Quien a mi entender da un golpe de timón radical respecto de una sensibilidad de época para la cuestión del ocultismo es Roberto Arlt, con su primer texto publicado en Tribuna libre: "Las ciencias ocultas en la ciudad de Buenos Aires", en 1920. A pesar de que durante varios años los diarios seguirán reseñando temas del mundo oculto, el texto de Arlt anuncia ya el retiro hacia lo residual de cierta forma de entender, vincularse y valorar las ciencias ocultas. Hay otra temporalidad que está hablando a través de Arlt. Y su texto mismo tiene la forma de un pasaje: cuando conoce al joven teósofo que lo inicia en sus primeras lecturas (que son ciertamente abundantes) y lo presenta en la Logia ViDharma, donde dos años antes el propio Ricardo Rojas daba su conferencia "El ideal de la nueva generación Argentina", ${ }^{12}$ Arlt experimenta un trance algo grotesco, producto de su intoxicación con lecturas teosóficas, pero trance visionario al fin. Ahora bien, cuando conoce a los miembros de la logia, su "desengaño" es grande: no ve más que obediencia y chatura intelectual, cierta "degeneración" y un camino hacia la locura, razón por la cual cita la novela La ciudad de los locos de Soiza Reilly (Arlt, 1999). Arlt ve la impostura de los ocultistas; a pesar de haber transitado por una importante porción de su bibliografía principal, o quizás gracias a ello, cae en la cuenta del cinismo y la mediocridad que se disfrazan tras grandes discursos cosmogónicos. No es casual que un personaje como Astrólogo fuera una futura creación de Arlt; nadie como él comprende que los discursos ideológicos pueden malearse con cinismo. Asimismo, Arlt es de los primeros que ligan la tarea de Annie Besant, líder de la Sociedad Teosófica, con el colonialismo inglés, esto es, que puede leer la política detrás de la volatilidad de los dobles astrales. Hay aquí, entonces, otra sensibilidad de época: la de aquel que ha querido creer, pero que ha descubierto la "treta". Nada más lejos que esa verdad independiente del discurso en la que férreamente creyó Lugones durante buena parte de su vida.

12 Dio su conferencia el 22 de diciembre de 1918. 


\section{Bibliografía}

Arlt, Roberto (1920). "Las ciencias ocultas en la ciudad de Buenos Aires", Tribuna libre, Buenos Aires, núm. 63, 28 de enero. Incluido en Roberto Arlt (1999). Nuevas Aguafuertes. Buenos Aires: Losada, 106-141.

Barcia, Pedro Luis (1998). “Estudio preliminar" a Lugones, Leopoldo. El espejo negro y otros cuentos. Buenos Aires: Huemul, 7-54.

Barrancos, Dora (1996). La escena iluminada. Ciencia para trabajadores. Buenos Aires: Plus Ultra.

Biagini, Hugo (comp.) (1986). El movimiento positivista argentino. Buenos Aires: Belgrano.

Capanna, Pablo (2010). Inspiraciones. Historias secretas de la ciencia. Buenos Aires: Paidós.

Conan Doyle, Sir Arthur [1926] (1952), El espiritismo; su historia, sus doctrinas, sus hechos, Buenos Aires, Schapire.

Darío, Rubén (1917). La caravana pasa. Madrid: Mundo Latino. Prólogo de Alberto Ghiraldo.

.(1950). Cuentos completos. México: FCE.

.(1968). Autobiografía. Buenos Aires: Eudeba.

Holmberg, Eduardo L. (1903). "Nunca se supo", Caras y Caretas, Buenos Aires, $\mathrm{n}^{\circ} 25018$ de julio.

(1906). "Un fantasma”, Caras y Caretas, Buenos Aires, n 419, 13 de octubre.

(1911). "Las luces malas", Caras y Caretas, Buenos Aires, $n^{\circ}$ 651, 25 de marzo.

[1959] (1994). Cuentos Fantásticos. Estudio Preliminar de Pagés Larraya, Antonio. Buenos Aires: Edicial.

Ingenieros, José (1897). “La ciencia oficial y la Facultad de Ciencias Herméticas", La Montaña. Periódico socialista revolucionario, Buenos Aires, $\mathrm{N}^{\mathrm{o}} 11$ (I), 11 de septiembre. 
.(1898). "Unilateralidad psicológica de los sabios oficiales", Philadelphia, 7 de noviembre.

.(1904). "Interpretación científica y valor terapéutico del hipnotismo y la sugestión", Constancia, Buenos Aires, 10, 17 y 24 de julio.

La Redacción (1906). "Ingenieros y las experiencias de Richet”. Constancia, Buenos Aires, 11 de febrero.

Lob-Nor (1915). “Una sesión de fenómenos psíquicos con el Dr. Aristóbulo del Valle", El Diario, 14 de octubre.

Lugones, Leopoldo (1896). "Primera edición: Nelly, por Eduardo L. Holmberg", El Tiempo, Buenos Aires, 18 de septiembre.

(1982). Cuentos desconocidos. Compilación y estudio preliminar de Pedro L. Barcia. Buenos Aires: Ediciones del 80.

(1988). El espejo negro y otros cuentos. Buenos Aires: Abril. Estudio preliminar, notas y vocabulario de Pedro Luis Barcia.

[1906; 1926] (1996). Las fuerzas extrañas. Edición a cargo de Arturo García Ramos. Madrid: Cátedra.

Mariño, Cosme (1963). El espiritismo en la Argentina, Buenos Aires, Constancia.

Quereilhac, Soledad (2010). "Ecos de Oriente en Buenos Aires: la teosofía” y "Sombras teosóficas en los relatos de Leopoldo Lugones". La imaginación científica. Ciencias ocultas y literatura fantástica en el Buenos Aires de entre-siglos (1875-1910), Tesis de doctorado inédita, Facultad de Filosofía y Letras, UBA.

Quiroga, Horacio (1926). "El espiritismo y la caja de fósforos", Caras y Caretas, Buenos Aires, $\mathrm{n}^{\circ} 1472,18$ de diciembre.

(1993). Todos los cuentos. Madrid: ALLCA XX - Unesco Fondo de Cultura Económica. Edición de Lafforgue, Jorge y Baccino Ponce de León, Napoleón. 
Rojas, Ricardo (1917). "La psiquina”, La Novela Semanal, nº 6, 24 de diciembre. Recopilado en Pierini, Margarita (comp.) (2009). Doce cuentos para leer en el tranvía. Una antología de La Novela Semanal. Bernal: UNQ, pp. 179-200.

S/A (1918). "Sesión medianímica con Fidanza", Constancia, Buenos Aires, 4 de agosto.

S / A (1906). "Fenómenos de aportes y fotografías experimentados en La Plata", Constancia, Buenos Aires, 11 de febrero y el 18 de marzo.

S / A (1918)."La primera sesión de Fidanza en la Capital", Constancia, Buenos Aires, 6 de octubre.

Senillosa, F., Peyret, A. (1885). Contestación de F. Senillosa a Mr. A. Peyret quien en un articulo que se transcribe sigue atacando al Espiritismo. Buenos Aires: M. Biedma.

Senillosa, Felipe (1891). Concordancia del espiritismo con la ciencia, tomo II. Buenos Aires: Imprenta Biedma.

Serié, Pedro (1903). "Carta Abierta al Dr. José Ingegnieros", Constancia, Buenos Aires, 22 de febrero.

(1903). "Carta Abierta", Constancia, Buenos Aires, 22 de febrero.

Soiza Reilly, Juan José (1912). “Las ciencias ocultas en Buenos Aires. El espiritismo", Fray Mocho, Buenos Aires, 22 de septiembre.

Terán, Oscar (2000). Vida intelectual en el Buenos Aires fin-de-siglo (18801910). Derivas de la cultura científica. Buenos Aires: Fondo de Cultura Económica.

Williams, Raymond [1961] (1993). La larga revolución. Buenos Aires: Nueva Visión.

Zanetti, Susana (comp.) (2004). Rubén Darío en La Nación de Buenos Aires. Buenos Aires: Eudeba. 